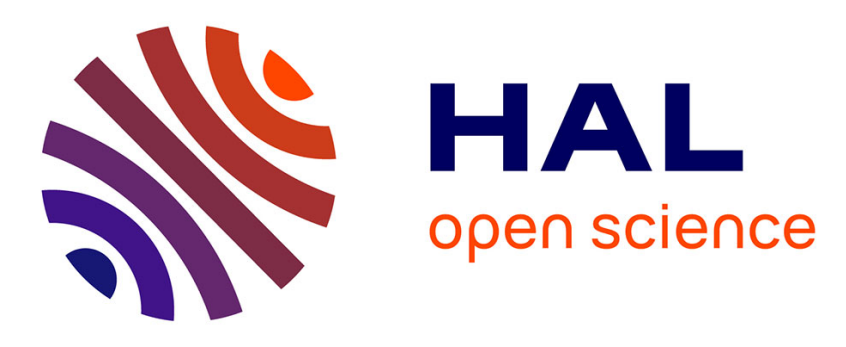

\title{
Design of Potassium-Selective Mixed Ion/Electron Conducting Polymers
}

Ariana Villarroel Marquez, Gerardo Salinas, Myriam Abarkan, Maël Idir,

Cyril Brochon, Georges Hadziioannou, Matthieu Raoux, Alexander Kuhn, Jochen Lang, Eric Cloutet

\section{To cite this version:}

Ariana Villarroel Marquez, Gerardo Salinas, Myriam Abarkan, Maël Idir, Cyril Brochon, et al.. Design of Potassium-Selective Mixed Ion/Electron Conducting Polymers. Macromolecular Rapid Communications, In press, 10.1002/marc.202070030 . hal-02564999

\section{HAL Id: hal-02564999 \\ https://hal.science/hal-02564999}

Submitted on 6 May 2020

HAL is a multi-disciplinary open access archive for the deposit and dissemination of scientific research documents, whether they are published or not. The documents may come from teaching and research institutions in France or abroad, or from public or private research centers.
L'archive ouverte pluridisciplinaire HAL, est destinée au dépôt et à la diffusion de documents scientifiques de niveau recherche, publiés ou non, émanant des établissements d'enseignement et de recherche français ou étrangers, des laboratoires publics ou privés. 


\section{WILEY-VCH}

1 Design of potassium selective mixed ion/electron conducting polymers biological cells and microorgans of interest in the field of biosensors and physiology.

Ariana Villarroel Marquez, Gerardo Salinas, Myriam Abarkan, Maël Idir, Cyril Brochon, Georges Hadziioannou, Matthieu Raoux, Alexander Kuhn, Jochen Lang, Eric Cloutet*

Dr. A. Villarroel Marquez, Maël Idir, Dr. Cyril Brochon, Prof. Georges Hadziioannou, Dr. Eric Cloutet Univ. Bordeaux, CNRS, Bordeaux INP, LCPO, UMR 5629, F-33615, Pessac, France E-mail: cloutet@u-bordeaux.fr

Dr. A. Villarroel Marquez, Myriam Abarkan, Dr. Matthieu Raoux, Prof. Jochen Lang Univ. Bordeaux, CNRS, Bordeaux INP, CBMN, UMR 5248, F-33600, Pessac, France.

Dr. G. Salinas, Prof. A. Kuhn

Univ. Bordeaux, CNRS, Bordeaux INP, ISM, UMR 5255, F-33607 Pessac, France.

Keywords: Mixed conducting polymers, PEDOT, crown-ether, ion sensing, coulovoltammetry.

An approach providing cation selective PEDOT:polyelectrolyte mixed conductors is presented in this communication, based on the structural modification of this ambivalent (ionic and electronic conductive) polymer complex. First, an 18-crown-6 moiety was integrated into the styrene sulfonate monomer structure as a specific metal cation scavenger particularly targeting $\mathrm{K}^{+}$vs $\mathrm{Na}^{+}$detection. This newly functionalized monomer has been characterized by ${ }^{1} \mathrm{H}-\mathrm{NMR}$ titration to evaluate the ion selectivity. Aqueous PEDOT dispersion inks containing the polymeric ion-selective moieties have been designed and their electrical and electrochemical properties have been analysed. These biocompatible inks are 


\section{WILEY-VCH}

1 Mixed conducting polymer films are materials that have gained considerable interest, due to

2 the synergy between the polyelectrolyte, for ionic transport, and the conjugated conducting

3 polymer, for electronic transport. ${ }^{[1-2]}$ Poly-(3,4-ethylenedioxythiophene) (PEDOT), ${ }^{[3]}$

4 stabilized by poly(styrene sulfonate) (PSS), is one of the most used mixed conducting

5 polymer system for the development of organic electronics. ${ }^{[4-6]}$ PSS has a double role in the

6 blend; it works as the counter ion for the conducting doped PEDOT chains and stabilizes the

7 insoluble charged PEDOT in aqueous suspensions. PEDOT:PSS dispersions have been used

8 to obtain thin film electrodes for different applications such as solar cells (OPV),

9 electrochromic electrodes, flexible screen devices (OLED) and organic electrochemical

transistors (OECTs). ${ }^{[4],[7-8]}$ In the latter, since mixed conduction occurs in the volume of these

11 devices, the low current resistance of the films allows better electrical recordings with local

12 signal amplification and consequently unprecedented signal detection in biology

13 applications ${ }^{[9-10]} \mathrm{pH}^{[11]}$ and ion monitoring. ${ }^{[12-13]}$ An interesting alternative is the enhancement

14 of ion selectivity of these materials by tuning the chemical structures of the conducting

15 polymer or the polyelectrolyte, in order to target an analyte of interest. ${ }^{[14]}$ Complex

16 functionalized polythiophenes, with selective moieties targeting anion and cation analysis

17 have been synthesized. ${ }^{[15-16]}$ Although these mixed conducting polymers present high selectivity, the poor solubility of the monomer in water imposes the use of organic solvents during the electropolymerization. In the frame of a more environmental friendly approach, a promising method to improve solubility may be provided by functionalization of the water soluble polyelectrolyte. In this work, we present an approach to confer cation selectivity to a PEDOT:polyelectrolyte mixed conductor. A specific metal cation scavenger particularly targeting $\mathrm{K}^{+}$detection, the 18 -crown- 6 moiety, was integrated into the styrene sulfonate monomer through the modification of the corresponding anion. The 18-crown-6 moiety has been chosen due to its well-known affinity towards the target cation $\mathrm{K}^{+}$, based on its size matching, as well as for the commercial availability of its functional derivatives (i.e. 


\section{WILEY-VCH}

1 aminocrown $).{ }^{[17]}$ Potassium $\left(\mathrm{K}^{+}\right)$was selected as a monovalent target among all the possible

2 choices, due to its importance in the generation and dissipation of electrical cell signals as

3 changes in $\mathrm{K}^{+}$efflux from cells play a major role in cell depolarization and repolarization of

4 membrane potentials. ${ }^{[18]}$ Incorporation of the ionophore 15-crown-5 in electrodeposited

5 PEDOT for monovalent cations analysis has been previously reported. ${ }^{[19]}$ However, the

6 electrodeposition requires the presence of different counter ions (PSS, chloride and

7 perchlorate) to keep the electroneutrality of the charged PEDOT chains.
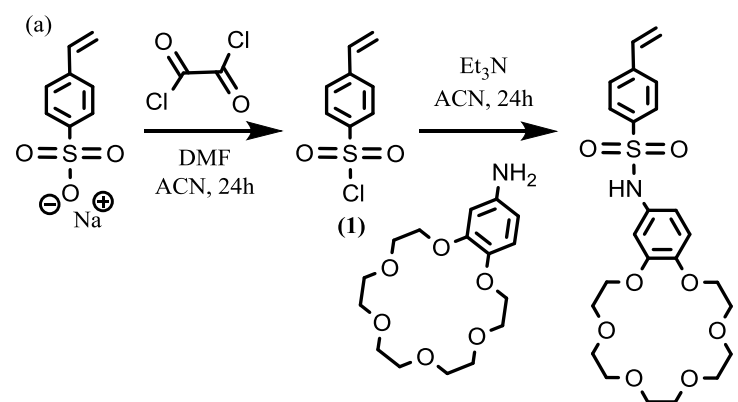

(2)

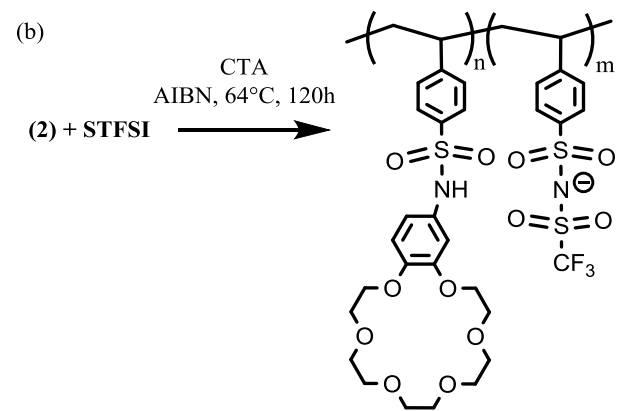

(3)

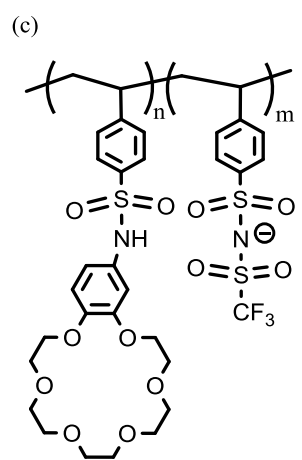

(3)
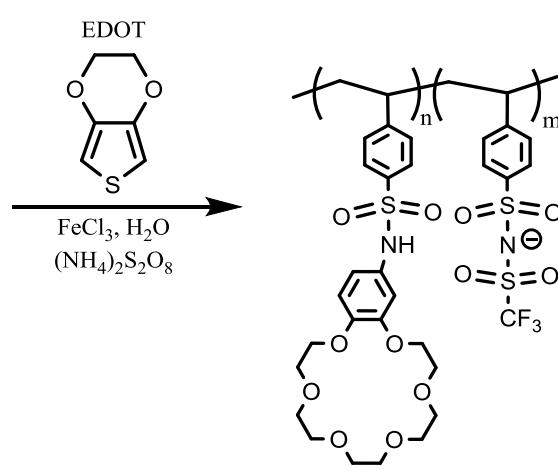

8

Scheme 1. (a) Synthetic route to obtain the 4-styrenesulfonyl(phenyl-18-crown-6) imide monomer (2); (b) RAFT copolymerization of PEDOT counterpart (3) in the presence of CTA: Chain transfer agent 2-(Dodecylthiocarbonothioylthio)-2-methylpropionic acid, AIBN: Initiator 2,2'-Azobis(2-methylpropionitrile) with $\mathrm{m}$ : fraction of 4-styrenesulfonyl (trifluoromethylsulfonyl) imide (STFSI) and n: fraction of monomer (2). (c) Synthesis of ionsensitive aqueous PEDOT dispersion by oxidative polymerization of EDOT in water in the presence of $\mathrm{FeCl}_{3}$ and $\left(\mathrm{NH}_{4}\right)_{2} \mathrm{~S}_{2} \mathrm{O}_{8}$. 


\section{WILEY-VCH}

1 Synthesis of the newly functionalized monomer (2) was confirmed by ${ }^{1} \mathrm{H}-\mathrm{NMR},{ }^{13} \mathrm{C}-\mathrm{NMR}$

2 and EIS-HRMS spectroscopy (see supporting information, monomer synthesis and

3 spectroscopy characterization). This functionalized monomer (2) was characterized by ${ }^{1} \mathrm{H}-$

4 NMR titration to evaluate its ion selectivity (i.e. $\mathrm{K}^{+}$vs $\mathrm{Na}^{+}$). Aqueous PEDOT dispersion inks

5 containing the ion-selective moieties were then designed and their electrical and

6 electrochemical properties have been analyzed. Synthesis of the ion selective monomer,

7 copolymerization of the polyelectrolyte and synthesis of the conductive inks are illustrated in

8 Scheme 1. First, the synthesis of (2) has been achieved in a two-step reaction path. The

9 formation of the styrenesulfonyl chloride (1) was followed by reaction with the functionalized amino phenyl-18-crown-6, to obtain the targeted monomer (2). The ${ }^{1} \mathrm{H}-\mathrm{NMR}$ spectrum of (2)

11 (Figure SI-1) shows the corresponding signals for the styrene aromatic protons at $7.4 \mathrm{ppm}$ and

$12 \quad 7.7 \mathrm{ppm}$. Vinyl protons are evidenced by the presence of the signals at $5.37 \mathrm{ppm}$ and 5.82 ppm. The signal of $-\underline{\mathrm{CH}}_{2}-\mathrm{O}$ - from the crown moiety is assigned at $3.75 \mathrm{ppm}$. Finally, the multiplet signal at $6.62 \mathrm{ppm}$ corresponds to the aromatic protons of the crown moiety. The corresponding ${ }^{13} \mathrm{C}-\mathrm{NMR}$ spectrum of (2) also confirms the expected monomer structure 16 (Figure SI-2).

17 Ion selectivity toward $\mathrm{K}^{+}$vs. $\mathrm{Na}^{+}$of newly designed monomer (2) was first investigated via $18{ }^{1} \mathrm{H}-\mathrm{NMR}$ titration at various concentrations of potassium and sodium perchlorate (Figure SI-3 and Figure SI-4). Figure 1 shows for instance the chemical shifts obtained during the NMR study of monomer (2) in the presence of 2 molar equivalents in concentration of potassium and sodium perchlorate, respectively. Thus, in the presence of $\mathrm{K}^{+}$, the signals related to the protons in the proximity of the crown ether cavity (signals 9-10 and 2-5) are shifted, as compared to the ${ }^{1} \mathrm{H}-\mathrm{NMR}$ spectrum of the pristine monomer (Figure $1 \mathrm{~b}$ vs. 1a) in the absence of $\mathrm{K}^{+}$. This behavior can be attributed to the formation of a coordination compound between the $\mathrm{K}^{+}$and the crown ether moiety (signals $2-3$ in Fig $1 \mathrm{~b}$ vs 1a). Furthermore, the chemical shifts related to the vinyl protons (signals 6-7) were not affected by the presence of the cation. 


\section{WILEY-VCH}

1 This confirms that the binding interaction with the monovalent cations occurs as expected

2 through the crown ether moiety. However, when ${ }^{1} \mathrm{H}-\mathrm{NMR}$ study was performed in the

3 presence of sodium perchlorate at the same concentration as $\mathrm{K}^{+}$, the variation of the chemical

4 shift was negligible (signals 2-3 in Figure 1c vs 1a). From the analysis of the chemical shift as

5 a function of the salt concentration the binding isotherms were obtained (Figure SI-5). Using a

$6 \quad 1: 1$ binding model of the experimental data, the association constants $\left(k_{a}\right)$ of (2) with both

7 cations were evaluated $\left(k_{a, N a}=121.7 \pm 6.9 \mathrm{M}^{-1}\right.$ and $\left.k_{a, K}=1026.2 \pm 118.3 \mathrm{M}^{-1}\right)$. As the $K_{a}$ is

8 one order of magnitude higher for potassium in comparison to sodium, these results confirm

9 the high selectivity of (2) for the $\mathrm{K}^{+}$cation in accordance with the crown ether size-matching

10 rule. In addition, from the dissociation constants $\left(k_{d}=1 / k_{a}\right)$, a stronger binding of $\mathrm{K}^{+}$in this

11 solvent can be inferred. Finally, saturation of the binding sites was obtained only by the

12 addition of the potassium salt (plateau range in figure SI- 5).

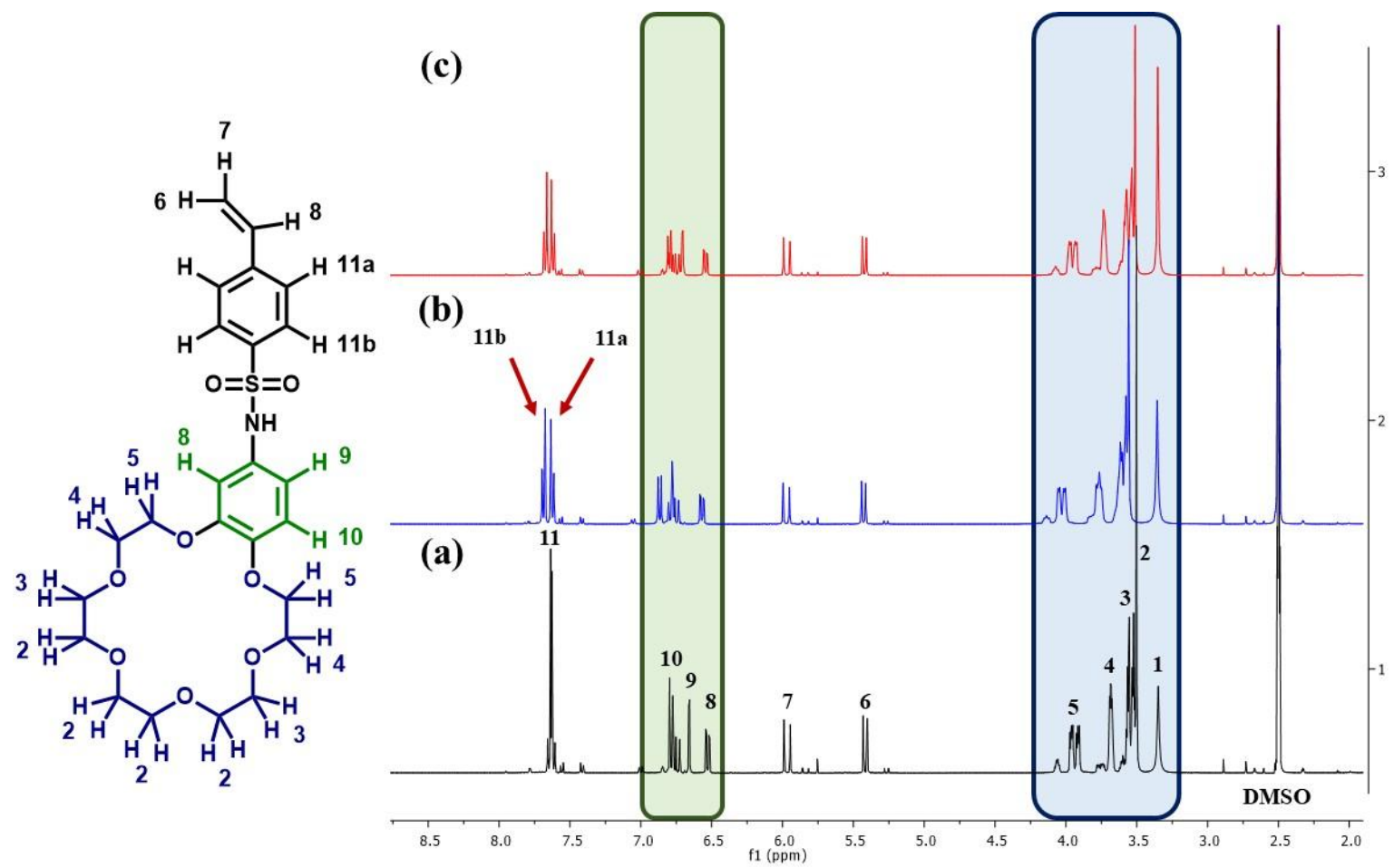

13

Figure 1. ${ }^{1} \mathrm{H}-\mathrm{NMR}$ Spectra (DMSO- $\mathrm{d}_{6}, 400 \mathrm{MHz}$ ) obtained for monomer (2) in the absence (a) and in the presence of 2 molar equivalents of (b) potassium perchlorate and (c) sodium perchlorate. 


\section{WILEY-VCH}

1 Monomer (2) was then integrated into a polyanion through copolymerization with the

2 monomer 4-styrenesulfonyl (trifluoromethylsulfonyl) imide (STFSI). PSTFSI derivative has

3 been reported by us as an alternative to PSS in PEDOT:PSS materials for further use in

4 transparent organic electrodes. ${ }^{[8],[20]}$ The STFSI fraction provides solubility in water, whilst

5 the functionalized monomer (2) confers the ion-sensitive ability. It appears that the dispersity

6 gets larger as the content in monomer (2) is increased, i.e. from 5 to $15 \%$ (Table 1) due to the

7 statistical distribution of these moieties in the different polymer chains. Moreover, when the content of the monomer (2) increases up to $40 \%$ or $50 \%$, it became complicated to reach the targeted chain length $(M w)$ (Table 1). A copolymer at a ratio of 85 wt. \% of STFSI and 15 wt. \% of monomer (2) has been taken as a case study from a larger copolymer family (Table 1). A polyanion P(STFSI-co-S(18-crown-6)) (3) with an apparent molar mass of $135 \mathrm{kDa}$, was for instance obtained (Figure SI-6, PS standard calibration and DMF solvent) with quite broad distribution which can be attributed to specific interactions with SEC columns. The ${ }^{1} \mathrm{H}-$ NMR of the P(STFSI-co-S(18-crown-6)) (Figure SI-7) clearly shows broadening of signals as compared to the initial monomers' spectra in accordance with the expected expansion of polymer signals in this type of high molar masses polyelectrolytes. ${ }^{[21]}$ The presented copolymer ratio is the theoretical weight percentage (wt $\%$ ) ratio between STFSI and monomer (2) used for the polymer synthesis. Experimentally it is not possible to quantify the copolymer ratio by the NMR spectra, as the initiator signal overlaps in the aliphatic region with the signals related to the alkyl polymer backbone $(\delta=0.75-2.25 \mathrm{ppm})$. However, the ${ }^{1} \mathrm{H}-$ NMR chemical shifts from the aromatic rings, polystyrene backbone and crown ether moieties could be assigned at $\delta=6.59-7.54 \mathrm{ppm}, \delta=1.44 \mathrm{ppm}$ and $\delta=3.53-4 \mathrm{ppm}$ respectively and thus confirmed the copolymer synthesis and correlates with the ratio between comonomers. ${ }^{21}$

Table 1. Summary of polyanion (3) synthesized, and used for the stabilization of ion-sensitive 
1 ratio between both monomers; $M w$ : Average of the apparent molecular mass $(\mathrm{kDa})$ of the

2 obtained polyanions copolymers ${ }^{\mathrm{a})}$ and $Đ$ : Dispersity as obtained from $\mathrm{SEC}^{\mathrm{a})}$ analysis in DMF

3 using PS standard calibration

\begin{tabular}{|c|c|c|c|}
\hline $\begin{array}{l}\text { Theoretical polyelectrolyte composition } \\
\qquad\left[\mathrm{M}^{\circ}{ }_{\mathrm{WT} \%}-\mathrm{M}_{\mathrm{WT} \%}\right]\end{array}$ & $\mathrm{n}_{\mathrm{m} 0} / \mathrm{n}_{\mathrm{M}}$ & $\mathrm{Mw}[\mathrm{kDa}]^{\mathrm{a})}$ & $\mathrm{D}^{\mathrm{a})}$ \\
\hline $\mathrm{PSS}_{95}-\mathrm{PS} 18 \mathrm{cr} 6_{5}$ & 13.6 & 112 & 1.3 \\
\hline PSTFSI $_{90}$-PS $18 \mathrm{cr} 6_{10}$ & 6.5 & 127 & 2.3 \\
\hline PSTFSI $_{85}-$ PS $18 \mathrm{cr} 6_{15}$ & 4.1 & 135 & 2.6 \\
\hline PSTFSI $_{85}-\mathrm{PS} 18 \mathrm{cr} 6_{15}(250 \mathrm{KDa})$ & 4.1 & 208 & 2.8 \\
\hline PSTFSI $_{70}-\mathrm{PS} 18 \mathrm{cr} 6_{30}$ & 1.7 & 144 & 2.3 \\
\hline PSTFSI $_{60}-$ PS $18 \mathrm{cr} 6_{40}$ & 1.1 & 44 & 1.4 \\
\hline PSTFSI $_{50}-\mathrm{PS} 18 \mathrm{cr} 6_{50}$ & 0.7 & 96 & 2.3 \\
\hline
\end{tabular}

5 The ion-sensitive functionalized polyelectrolyte, P(STFSI-co-S(18-crown-6)), was

6 subsequently used as a stabilizer/counterpart of aqueous PEDOT dispersions during the

7 oxidative in-situ polymerization of $\mathrm{EDOT}^{[21]}$ in the presence of iron chloride and ammonium

8 persulfate; see Scheme 1c). PEDOT inks were obtained after polymerization for $64 \mathrm{~h}$ at $10^{\circ} \mathrm{C}$

9 under inert atmosphere, then recovered through purification via ultrafiltration. As illustrative

10 example, an initial copolymer solution (Figure SI-8a) is presented, acting as stabilizer of

11 PEDOT favoring the complex formation and stability of the PEDOT dispersion in water when

12 the polymerization takes place (Figure SI-8b).

13 Processable and stable aqueous inks were obtained, containing the hydrophobic ion-selective 14 moiety in the polyelectrolyte chains. However, stable PEDOT inks were difficult to obtain 15 when trying to incorporate more than $50 \%$ (in weight content) of crown ether modified 16 styrene subunits into the copolymer. In fact, in these cases the dispersion was unstable and the 17 polymer precipitated. Spin-coated PEDOT films presented conductivities in the $\mathrm{mS}^{-1}$ 18 range $\left(\sigma<1366 \mathrm{mS} \mathrm{cm}^{-1}\right)$. Although this is less than what is observed for PEDOT:PSS and 19 PEDOT:PSTFSI (190 S cm$~^{-1}$ and $110 \mathrm{~S} \mathrm{~cm}^{-1}$ respectively), this conductivity range is 20 sufficient for bioelectronics applications. 


\section{WILEY-VCH}

1 In order to evaluate the electrochemical properties of the films and provide more evidence for

2 the occurrence of ion selectivity of these mixed conducting polymers, in-situ electrochemical

3 conductance experiments were carried out. ${ }^{[22]}$ The electrochemical characterization of drop

4 casted films was evaluated in an aqueous $0.1 \mathrm{M}$ tetramethyl ammonium chloride (TMAC)

5 solution (Figure 2a and b). Two separate IDME electrodes, covered with the same conductive

6 ink, were used to analyze their electrochemical response in the presence of potassium and

7 sodium respectively (Figure $2 \mathrm{a}$ and $\mathrm{b}$ ). Since during drop casting, the thickness control of the

8 films is limited, normalized currents are presented in order to allow a reasonable comparison

9 of the samples.

Initially, during the first potential sweep, peaks of current were not observed for both films

11 (Fig. 2 (a) and (b)). Subsequently, a peak of current starts to appear, between $0.36 \mathrm{~V}$ and 0.38

$12 \mathrm{~V} v \mathrm{Ag}^{\circ}$. This additional anodic reaction is attributed to the oxidation of the aniline moiety attached to the crown ether group along the P(STFSI-co-S(18-crown-6)) polyanion. The absence of this oxidation peak, at the first potentiodynamic scan, is due to the low current attributed to such redox process, which overlaps with the oxidation current of the different oligomeric PEDOT chains. It should be noted that PEDOT:PSS and PEDOT:PSTFSI do not show any anodic peak in this range of potentials (Figure SI-9a and b). The conductance profile of the films shows a quasi-linear increase during the potential sweep, caused by the formation of mobile charges in the PEDOT backbone. Whereas, a gradual decrease of conductance was observed as the cycling proceeds (from $5.44 \pm 0.75 \mathrm{mS}$ to $4.61 \pm 0.37 \mathrm{mS}$ ) (Figure SI-10a and b). This decrease is attributed to a conformational rearrangement of the oligomeric chains of the polymer blend and not to a limitation of charge hopping caused by the trapped positive charges formed during the aniline oxidation. ${ }^{[23]}$ In order to provide more evidence of these conformational changes, the charge-potential plots were obtained by integration of the potentiodynamic plots. ${ }^{[2]}$ From the coulovoltammetric response it is 


\section{WILEY-VCH}

1 inside the conducting polymer matrix. ${ }^{[25-28]}$ These charge-potential plots have been used by

2 Otero et al., by means of the electrochemically stimulated conformational relaxation model

3 (ESCR) to explain the reversible and irreversible structural changes driven by electrochemical

4 reactions of conducting polymers exchanging cations. ${ }^{[29]}$ Since, for mixed conducting

5 materials, composed of conducting polymers and anionic polyelectrolytes, the anion remains

6 inserted in the conducting polymer matrix during the charge/discharge process, exchange of

7 cations occurs. According to the ESCR model, variations in the slope values of the charge-

8 potential plots are attributed to conformational changes of the polymer matrix. ${ }^{[2]}$

9 The coulovoltammetric response of the films, in a 0.1 M TMAC aqueous solution (Figure SI-

10 11a), presents in the first cycle, starting from the minimum of charge, two oxidation

11 processes: an oxidation/shrinking $\left(m_{O / S}=0.48 \mathrm{mC} \mathrm{V}^{-1}\right)$ and an oxidation/compaction ${ }^{[30]}\left(m_{O / C}\right.$

$\left.12=0.78 \mathrm{mC} \mathrm{V}^{-1}\right)$, both caused by the release of cations from the polymer matrix. The latter is

13 followed, at the beginning of the cathodic sweep, by some oxidation inertia and two reduction

14 processes: a reduction/relaxation $\left(m_{R / R}=0.16 \mathrm{mC} \mathrm{V}^{-1}\right)$ and a reduction/swelling $\left(m_{R / S}=0.50\right.$

$15 \mathrm{mC} \mathrm{V}^{-1}$ ), caused by the insertion of tetramethyl ammonium cations. During subsequent scans,

16 the slope value of the oxidation/shrinking and the oxidation/compaction slope decreases

17 (Figure SI-11b, $m_{O / S}=0.26 \mathrm{mC} \mathrm{V}^{-1}, m_{O / C}=0.46 \mathrm{mC} \mathrm{V}^{-1}$ ), whilst a new oxidation process

18 appears, between $0.30 \mathrm{~V}$ and $0.45 \mathrm{~V}$ vs $\mathrm{Ag}^{\circ}$, with a concomitant increase of slope $\left(m_{A n / S}=\right.$

$190.81 \mathrm{mC} \mathrm{V}^{-1}$ ). Due to the range of potential where it appears, this is attributed to the positive

20 charge formed during the aniline oxidation ${ }^{[31]}$ that, in addition to the oxidation of PEDOT,

21 causes a faster oxidation/shrinking process, hereafter referred to as aniline-

22 oxidation/shrinking. Finally, during the cathodic sweep, a faster reduction/swelling process

23 was observed $\left(m_{R / S}=0.77 \mathrm{mC} \mathrm{V}^{-1}\right)$. This may be attributed to a positive "charge trapping",

24 which requires a faster exchange of cations and anions inside the polymer matrix to keep

25 electroneutrality. 


\section{WILEY-VCH}

1 The ion selectivity was evaluated in a $0.1 \mathrm{M}$ TMAC aqueous solution in the presence of 10

$2 \mathrm{mM}$ potassium or sodium chloride (Figure $2 \mathrm{c}$ and $\mathrm{d}$, respectively). In the presence of $\mathrm{KCl}$, a

3 continuous decrease in current of the aniline oxidation peak (20.5\%) was observed. In

4 contrast, in the $\mathrm{NaCl}$ solution, first a small decrease of the aniline oxidation peak was

5 obtained, followed by a slow increase of the peak current (2.4\%). A possible explanation for

6 this observation is that potassium ions provide an electron withdrawing effect on the aniline

7 moiety, which causes an anodic shift of the oxidation potential of the aniline. Thus, the amount of aniline present and able to get oxidized at $0.38 \mathrm{~V}$ vs $\mathrm{Ag}^{\circ}$ decreases as the cycling proceeds. The absence of an oxidation peak for the new $\mathrm{K}^{+}$-aniline complex, is due to the low current attributed to such a redox process, which may overlap with the oxidation current of

11 the different oligomeric PEDOT chains as it was stated previously. In the presence of sodium,

12 the cation does not fit into the crown ether cavity and it is easier to oxidize the aniline moiety.

13 Finally, for both cations, the conductance profile of the films shows the same quasi-linear 14 variation during the potential sweep, whereas a small decrease of conductance was observed as a function of the potential scans $\left(\Delta G_{p-K}=0.17 \pm 0.01 \mathrm{mS}\right.$ and $\left.\Delta G_{p-N a}=0.28 \pm 0.11 \mathrm{mS}\right)$ (Figure SI-10a and b). Thus, the charge hopping process is not influenced by the presence of different cations. $^{[23]}$

From the charge-potential plots of the films, in the presence of $\mathrm{KCl}$ and $\mathrm{NaCl}$ (Figure 2e and $\mathrm{f}$, respectively), the change of the maximum oxidation charge $(\Delta Q)$ after 10 potentiodynamic cycles was evaluated $\left(\Delta Q_{K}{ }^{+}=88.70 \pm 1.59 \mu \mathrm{C}\right.$ and $\left.\Delta Q_{N a}{ }^{+}=48.31 \pm 5.65 \mu \mathrm{C}\right)$. As the $\Delta Q$ for potassium is the double in comparison to sodium, these results confirm the selectivity of the films for the $\mathrm{K}^{+}$cation in accordance with the size-matching rule. In addition, the coulovoltammetric response presents, for all the cycles, the same oxidation/reduction process as in the absence of the monovalent cations (Figure 2e and f). As the experiment proceed, changes on the slope for all the oxidation/reduction process can be observed. From the charge-potential plots (Figure 2e and $\mathrm{f}$, respectively), it can be seen a higher variation of the 


\section{WILEY-VCH}

1 slope for the aniline-oxidation/shrinking and the reduction/swelling process. In the presence

2 of $\mathrm{K}^{+}$the aniline-oxidation/shrinking and the reduction/swelling present a decrease in the

3 slope value $\left(\Delta m_{A n / S K}=-0.19 \mathrm{mC} \mathrm{V}^{-1}, \Delta m_{R / S} K=-0.03 \mathrm{mC} \mathrm{V}^{-1}\right)$. However, in the $\mathrm{NaCl}$ solution,

4 both processes show an increase in the slope value $\left(\Delta m_{A n / S N a}=0.08 \mathrm{mC} \mathrm{V}^{-1}, \Delta m_{R / S N a}=0.10\right.$

$5 \quad \mathrm{mC} \mathrm{V}^{-1}$ ). Since potassium ions, trapped inside the crown ether cavity, are not expelled during

6 the aniline-oxidation/shrinking process, an abrupt rearrangement of the oligomeric chains

7 (between $1^{\text {st }}$ and $2^{\text {nd }}$ cycle) followed. This may be due to a slow mass insertion/repulsion of

8 ions during the charge/discharge process. These results correlate with the binding constants

9 obtained by ${ }^{1} \mathrm{H}-\mathrm{NMR}\left(k_{a, N a}=121.7 \pm 6.9 \mathrm{M}^{-1}\right.$ and $\left.k_{a, K}=1026.2 \pm 118.3 \mathrm{M}^{-1}\right)$, where the

10 binding constant for potassium, suggests the formation of a $\mathrm{K}^{+}$-aniline complex inside the

11 polymer matrix. Such a high value of a binding constant is the first indicator of a poor release

12 of $\mathrm{K}^{+}$trapped in the $\mathrm{K}^{+}$-aniline complex. 

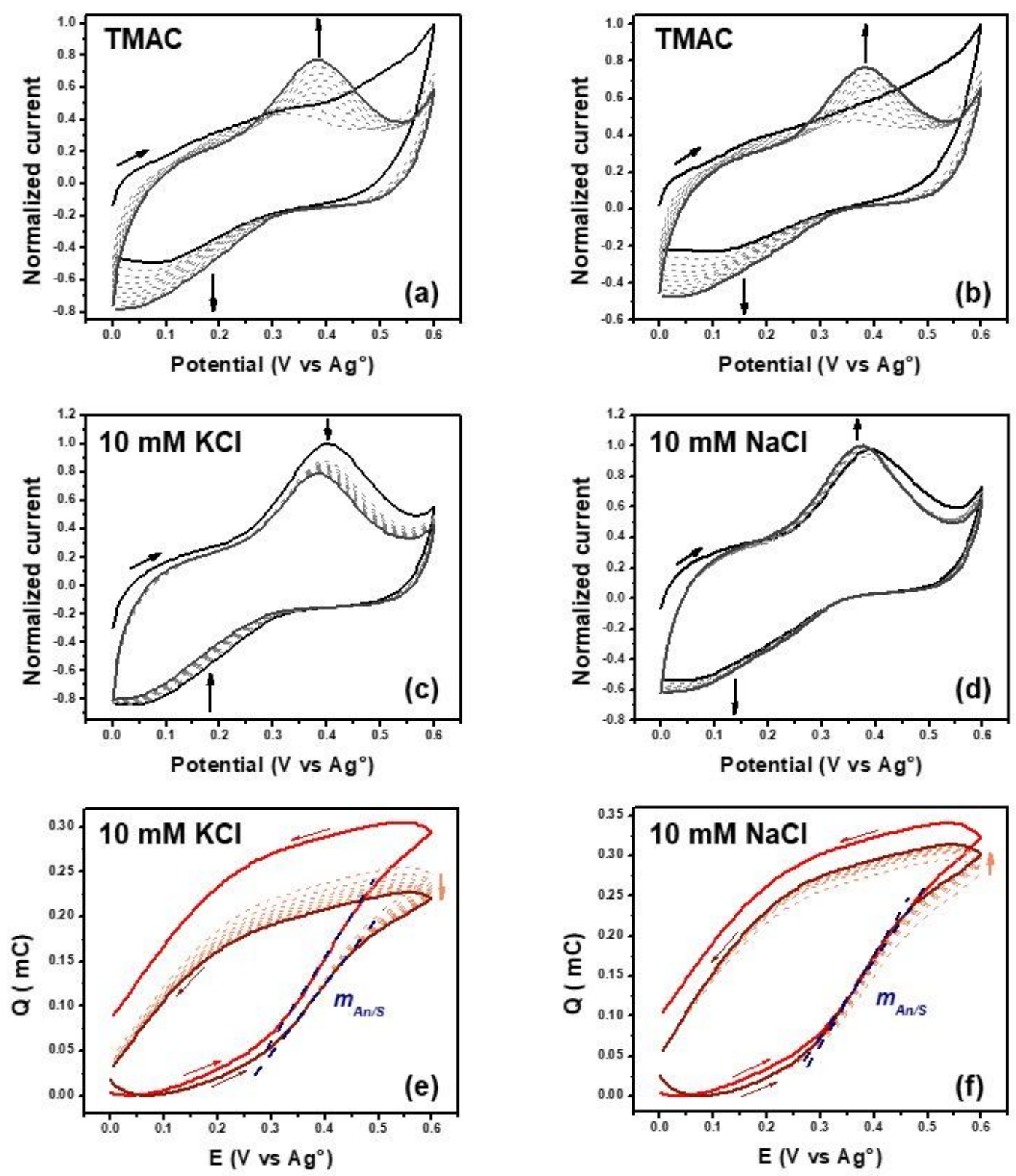

Figure 2. Potentiodynamic study of drop casted PEDOT/ P(STFSI $\left.85-c o-S 18 \mathrm{cr} 6_{15}\right)$ films in a

$30.1 \mathrm{M}$ TMAC aqueous solution using $E_{\lambda}=0.6 \mathrm{~V}^{\mathrm{vs} \mathrm{Ag}} \mathrm{Ag}^{\circ}, 10$ cycles, $v=10 \mathrm{mV} \mathrm{s}^{-1}$ and $\Delta V$ on

4 the $\mathrm{WE}=10 \mathrm{mV}, \mathrm{WE}=\mathrm{Pt}$ IDMAE, $\mathrm{CE}=\mathrm{Pt}$ foil, in the absence ( $\mathrm{a}$ and $\mathrm{b}$ ) and in the presence 5 of (c) $10 \mathrm{mM} \mathrm{KCl}$ and (d) $10 \mathrm{mM} \mathrm{NaCl}$. Charge-potential plots in the presence of (e) $10 \mathrm{mM}$ $6 \mathrm{KCl}$ and (f) $10 \mathrm{mM} \mathrm{NaCl}$.

7 Finally, in order to prepare for a future integration of these new ion-sensitive mixed conducting polymer complexes with biological systems, cell viability was evaluated on such PEDOT films. The quantification of the ratio between dead and total number of cells (dead + alive) grown on these films was comparable to the one in control conditions, suggesting an 


\section{WILEY-VCH}

1 unchanged growth of $\beta$ cells on the coverslips covered with films (Figure 3). Thus the

2 polymer material does not exhibit a major cytotoxic effect under the conditions tested. These

3 results open up the possibility of interfacing these ion-sensitive polymers with pancreatic $\beta$ -

4 cells, who play a key role in nutrient homeostasis and in diabetes. ${ }^{[18],[32]}$

5 In conclusion, a new approach was presented to introduce cation selectivity in a mixed

6 conducting polymer material. A specific metal cation scavenger, particularly targeting $\mathrm{K}^{+}$,

7 was integrated in the PEDOT: PSTFSI complex through the polyanion counterpart by

8 appropriate modification of the styrene subunits. We achieved synthesis and characterization

9 of a functionalized styrene derivative with an ion-selective moiety, i.e. 18-crown-6, monomer

10 (2). This monomer was used for the synthesis of a polyanion copolymer, which was then used

11 as a substitute to PSS in the oxidative dispersion polymerization of EDOT in water. All these

12 new compounds have been evaluated for their ability to sense $\mathrm{K}^{+}$metal cations. First,

13 monomer (2) showed a higher affinity for $\mathrm{K}^{+}$compared to $\mathrm{Na}^{+}$. Second, the PEDOT inks

14 composed of such polyanions displayed interesting new electrical and electrochemical

15 characteristics. By in-situ electrochemical conductance measurements and the correspondent

16 charge-potential plots, the higher affinity for $\mathrm{K}^{+}$as compared to $\mathrm{Na}^{+}$of these PEDOT

17 materials has been confirmed. Finally, these materials were not cytotoxic and therefore

18 qualify for applications such as recordings of $\mathrm{K}^{+}$-dependent electrical signals in pancreatic $\beta$ -

19 or other cells via the fabrication of ion selective OECTs. 

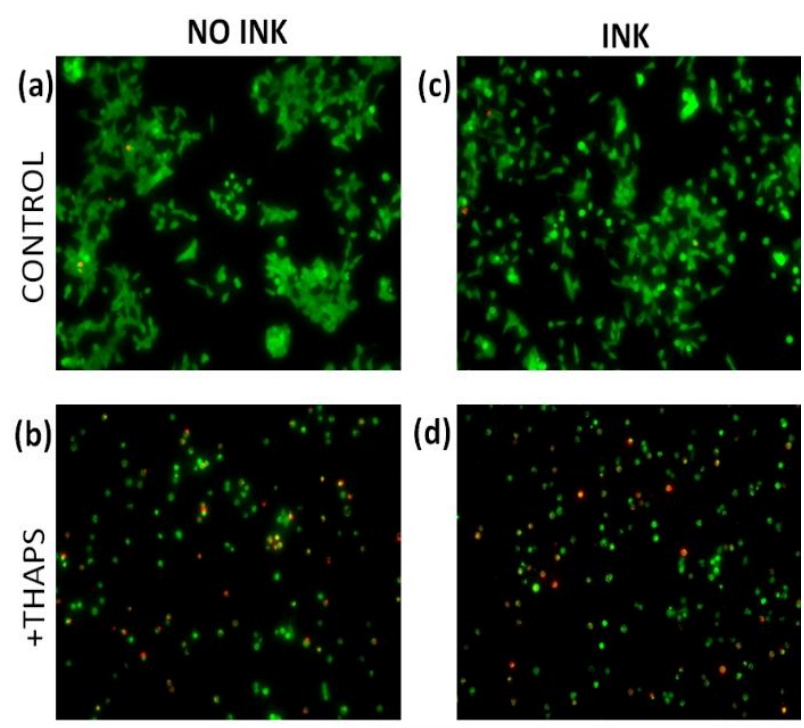

(e)
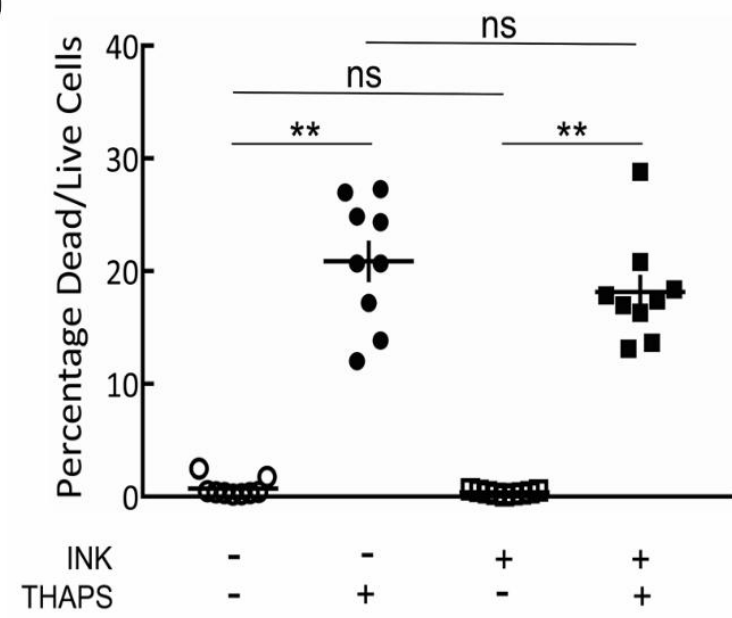

Figure 3. Cytotoxicity study of the ion sensitive inks: Clonal $\beta$ cells (INS832-13) cultured for $72 \mathrm{~h}$ on $(\mathrm{a}, \mathrm{c})$ control coverslips or coverslips covered with the ink studied (PEDOT: PSTFSI85-co-P(2)-15 with 18-crown-6 moieties). (b, d) Apoptosis induced by thapsigargin (6h, 10 $\mu \mathrm{M})$ on control coverslips or coverslips covered with the same ink. All micrographs present merged images (green: FYTC filter, live cells; red: YFP filter, dead cells). (e): quantitative assessment of apoptosis. Given are individual data points, means and SEM; $N=9$. **, $\mathrm{p}<0.001$; ns, not significant (Kruskal Wallis and Dunne post-hoc test)

\section{Supporting Information}

Supporting Information is available from the Wiley Online Library or from the author.

\section{Acknowledgements}

We are grateful for funding from the LabEx AMADEUS-0042 with the help of the French government "Initiative d'excellence" (to EC and JL), from ANR MULTISPOT ANR-17CE09-0015 (to EC, AK and JL) and the IDEX/CNRS PEPS "MULTISEPT" attributed to M.R. Authors thank for help from the staff of ELORPrintTec (ANR-10-EQPX-28-01) and LCPO / Arkema / ANR Industrial Chair 'HOMERIC' (ANR-13-CHIN-0002-01), as well as Eva M. Muñoz from Affinimeter. 


\section{WILEY-VCH}

Received: ((will be filled in by the editorial staff))

Revised: ((will be filled in by the editorial staff)) Published online: ((will be filled in by the editorial staff))

\section{References}

[1] C. M. Pacheco-Moreno, M. Schreck, A. D. Scaccabarozzi, P. Bourgun, G. Wantz, M. M. Stevens, O. J. Dautel, N. Stingelin, Adv. Mater. 2017, 29, 1604446.

[2] S. Inal, G. G. Malliaras, J. Rivnay, Nat. Comm. 2017, 8, 1767.

[3] L. B. Groenendaal, F. Jonas, D. Freitag, H. Pielartzik, J. R. Reynolds, Adv. Mater. 2000, 12,481 .

[4] Y. Wen, J. Xu, J. Pol. Sci. A 2017, 55, 1121.

[5] M. Berggren, X. Crispin, S. Fabiano, M. P. Jonsson, D. T. Simon, E. Stavrinidou, K. Tybrandt, I. Zozoulenko, Adv. Mater. 2019, 31, 1805813.

[6] H. Shi, C. Liu, Q. Jiang, J. Xu, Adv. Electron. Mater. 2015, 1, 1500017.

[7] J. H. Kim, C. W. Joo, J. Lee, Y. K. Seo, J. W. Han, J. Y. Oh, J. S. Kim, S. Yu, J. H. Lee, J. I. Lee, C. Yun, B. H. Choi, Y. H. Kim, Macro. Rapid. Comm. 2016, 37, 1427.

[8] A. I. Hofmann, E. Cloutet, G. Hadziioannou, Adv. Electron. Mater. 2018, 4, 1700412.

[9] D. Khodagholy, T. Doublet, P. Quilichini, M. Gurfinkel, P. Leleux, A. Ghestem, E. Ismailova, T. Hervé, S. Sanaur, C. Bernard, G. G. Malliaras, Nat. Commun. 2013, 4, 1575.

[10] P.-O. Svensson, D. Nilsson, R. Forchheimer, M. Berggren, Appl. Phys. Lett. 2008, 93, 203301.

[11] F. Mariani, I. Gualandi, M. Tessarolo, B. Fraboni, E. Scavetta, ACS Appl. Mater. Interfaces 2018, 93, 203301.

[12] U. Lange, N. V. Roznyatovskaya1, V. M. Mirsky, Anal. Chim. Acta 2008, 614, 1.

[13] D. T. McQuade, A. E. Pullen, T. M. Swager, Chem. Rev. 2000, 100, 2537.

[14] J. G. Ibanez, M. E. Rincon, S. Gutierrez-Granados, M. Chahma, O. A. JaramilloQuintero, B. A. Frontana-Uribe, Chem. Rev. 2018, 118, 4731. 


\section{WILEY-VCH}

1 [15] A. Aydogan, A. Koca, M. K. Şener, J. L. Sessler, Org. Lett. 2014, 16, 3764.

2 [16] S. Wustoni, C. Combe, D. Ohayon, M. H. Akhtar, I. McCulloch, S. Inal, Adv. Funct.

$3 \quad$ Mater. 2019, 1904403.

4 [17] J. M. Lehn, J. P. Sauvage, J. Chem. Soc. D 1971, 9, 440.

5 [18] J. Tien, D. M. Young, Y. N. Jan, L. Y. Jan, in From Molecules to Networks, (J. H.

6 Byrne, R. Heidelberger, M.N. Waxham), Academic Press: Boston, 2014, p 323.

7 [19] M. Jeszke, K. Trzcinski, J. Karczewski, E. Luboch, Electrochim. Acta 2017, 246, 424.

8 [20] M. Mumtaz, K. Aissou, D. Katsigiannopoulos, C. Brochon, E. Cloutet, G.

$9 \quad$ Hadziioannou, RSC Advances 2015, 5, 98559

10 [21] A. I. Hofmann, W. T. T. Smaal, M. Mumtaz, D. Katsigiannopoulos, C. Brochon, F.

11 Schütze, O. R. Hild, E. Cloutet, G. Hadziioannou, Angew. Chem. Int. Ed. 2015, 54, 8506.

12 [22] G. Salinas, B. A. Frontana-Uribe, ChemElectroChem 2019, 6, 4105.

13 [23] H.-h. Yu, A. E. Pullen, M. G. Buschel, T. M. Swager, Angew. Chem. Int. Ed. 2004, 43,

143700.

15 [24] T. F. Otero, Electrochim. Acta, 2016, 212, 440.

16 [25] T. F. Otero, M. Alfaro, V. Martinez, M. A. Perez, J. G. Martinez, Adv. Funct. Mater. $17 \mathbf{2 0 1 3}, 23,3929$.

18 [26] T. F. Otero, S. Beaumont, Sensors and Actuators B, 2017, 253, 958.

19 [27] T. F. Otero, S. Beaumont, Electrochim. Acta, 2017, 258, 1293.

20 [28] T. F. Otero, S. Beaumont, Electrochim. Acta, 2017, 257, 403.

21 [29] T. F. Otero, L. Valero, J. G. Martinez, Electrochim. Acta, 2017, 246, 89.

22 [30] According to the ESCR model an oxidation/shrinking process is associated to the pdoping of PEDOT with the expulsion of cations and solvent, whilst an oxidation/compaction is associated to the conformational movements of the chains in order to occupy the unoccupied volume left by the cations and solvent molecules.

[31] G. Ćirić-Marjanović, Synth. Met. 2013, 177, 1. 


\section{WILEY-VCH}

1 [32] D. A. Koutsouras, R. Perrier, A. Villarroel Marquez, A. Pirog, E. Pedraza, E. Cloutet,

2 S. Renaud, M. Raoux, G. G. Malliaras, J. Lang, J. Mat. Sci \& Eng. C 2017, 81, 84.

3 


\section{WILEY-VCH}

$1 \quad$ ToC text: Differentiating and sensing $\mathrm{K}^{+}$cations $v s \mathrm{Na}+$ through specific functionalization of 2 mixed conducting PEDOT complexes

3

Keywords Mixed conducting polymers, PEDOT, crown-ether, ion sensing, coulovoltammetry

\section{Author 2, D. E. F. Author 3, A. B. Corresponding Author* Ariana Villarroel Marquez,} Gerardo Salinas, Myriam Abarkan, Maël Idir, Cyril Brochon, Georges Hadziioannou, Matthieu Raoux, Alexander Kuhn, Jochen Lang, Eric Cloutet*

Title Design of potassium selective mixed ion/electron conducting polymers

\section{ToC figure}

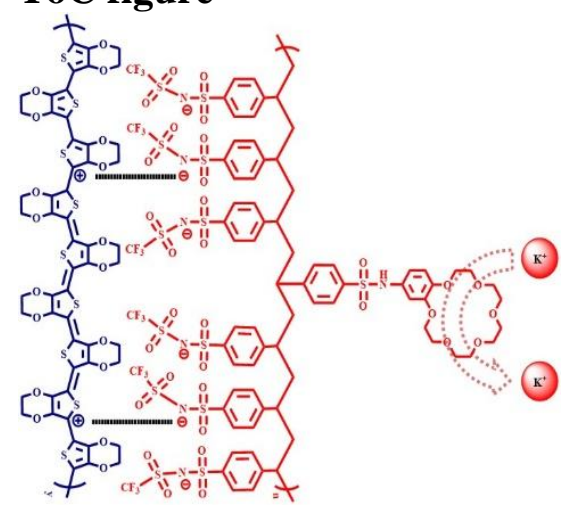




\section{WILEY-VCH}

Copyright WILEY-VCH Verlag GmbH \& Co. KGaA, 69469 Weinheim, Germany, 2018.

\section{Supporting Information}

\section{Design of potassium selective mixed ion/electron conducting polymers}

Ariana Villarroel Marquez, Gerardo Salinas, Myriam Abarkan, Maël Idir, Cyril Brochon, Georges Hadziioannou, Matthieu Raoux, Alexander Kuhn, Jochen Lang, Eric Cloutet*

\section{Chemicals}

4'-aminobenzo-18-crown-6; 4-styrene sulfonic acid sodium salt; 4-vinylbenzyl chloride; azobisisobutyronitrile; oxalyl chloride; potassium carbonate; sodium carbonate; triethylamine and all other products were used as received or according to manufacturer's instructions (Sigma Aldrich, France). N,N-dimethylformamide (DMF) was distilled from calcium hydride $\left(\mathrm{CaH}_{2}\right)$ prior to use. Acetonitrile was distilled prior to use or dried by a solvent dryer machine (MB SPS-800, MBraun). Tetrahydrofurane was distilled from benzophenone/sodium prior to use.

\section{Techniques and instrumentation}

Nuclear magnetic resonance (NMR) spectroscopy: ${ }^{1} \mathrm{H}-\mathrm{NMR}$ and ${ }^{13} \mathrm{C}-\mathrm{NMR}$ spectra for structural characterization and titration experiments were recorded on Bruker Avance $(300 \mathrm{MHz})$ and Bruker Prodigy $(400 \mathrm{MHz})$ spectrometers, respectively, at $300 \mathrm{~K}$ and the residual proton signal of the solvent was used as the internal standard. Size exclusion chomathography (SEC) was used to determine molar masses and dispersity of the copolymers synthesized. The system (Agilent GPC220HT) is equipped with UV and RI detectors and is equipped with a pre-column GF-1G-7B and two columns Asahipack GF-7MHSi (DMF, 0.1M $\mathrm{LiBr}, \mathrm{T}=75^{\circ} \mathrm{C}$, flow rate $\left.=0.6 \mathrm{~mL} / \mathrm{min}\right)$. Polystyrene standards were used for calibration. Film Deposition: A Brewer Science 200CBX spin-coater was used for film deposition. Substrates 


\section{WILEY-VCH}

1 were cleaned with a VWR ultrasonic cleaner. UV-ozone treatment was carried out using a

2 UVO cleaner 42A-220 from Jelight company inc. A Bruker Dektak XT-A profilometer was

3 used to measure film thickness.

4 NMR titrations: Supramolecular titration experiments have been carried out at constant 5 concentration of the monomer under study (host) and increasing concentrations of the salt.

6 Spectra were recorded for every sample, observing the change in the chemical shift in the case

7 of ${ }^{1} \mathrm{H}-\mathrm{NMR}$ spectroscopy. Variations in the chemical shift observed in ${ }^{1} \mathrm{H}-\mathrm{NMR}$ spectroscopy

8 were fitted to a 1:1 binding model using Affinimeter ${ }^{[1]}$ software and from these data the global

9 association constants were extracted.

10 Monomer synthesis and spectroscopy characterization

11 Step 1- Formation of 4-styrenesulfonyl chloride (1): A round bottom flask, previously flame12 dried, was charged with dry and degassed acetonitrile ( $\mathrm{V}=60 \mathrm{~mL})$. Oxalyl chloride $(5.91 \mathrm{~g}$, $1346.6 \mathrm{mmol}, 1.2$ eq.) and DMF were added. This solution was kept under stirring at room 14 temperature to solubilize the reagents and promote the Vilsmaier-Haack complex formation 15 for 4 or 5 hours. Once the characteristic yellow colour of the solution became stable, 416 styrenesulfonic acid sodium salt $(8.0 \mathrm{~g}, 38.8 \mathrm{mmol}, 1.0 \mathrm{eq}$.) was added slowly to the solution 17 under nitrogen atmosphere and at room temperature. After $24 \mathrm{~h}$ of reaction, the precipitated 18 salt was separated by filtration and the reaction mixture was used in the second step. second flame-dried round bottom flask containing dry and degassed acetonitrile $(\mathrm{V}=50 \mathrm{~mL})$,

21 triethylamine (4.29 g, $30.2 \mathrm{mmol}, 3$ eq.) and 4'-aminobenzo-18-crown-6 (3.00 g, $10.1 \mathrm{mmol}$,

221 eq.) were added and stirred for one hour. During this time, the 4-styrenesulfonyl 23 chloride/acetonitrile solution (formed during Step 1) was cooled at $0{ }^{\circ} \mathrm{C}$. Subsequently, the 24 trifluorosulfonamide solution was added in vacuum atmosphere to the former. Finally, the 


\section{WILEY-VCH}

1 mixture was allowed to warm up to room temperature and the reaction was kept running

2 under stirring for $16 \mathrm{~h}$. Purification was done firstly by removing under low pressure the

3 solvent mixture and solubilizing the monomer in dichloromethane. The product was obtained

4 by extraction with potassium carbonate and a subsequent wash with $1 \mathrm{M}$ hydrochloric acid

5 solution. Solvent was removed under low pressure and after drying overnight at $45^{\circ} \mathrm{C}$ under

6 vacuum, the product was recovered as a brown solid product. (yield=54\%). Scheme $1 .{ }^{1} \mathrm{H}-$

$7 \quad$ NMR (400 MHz; d-DMSO; 298K): $\delta(\mathrm{ppm})=7.79(\mathrm{~d}, 2 \mathrm{H}) ; 7.61(\mathrm{~d}, 2 \mathrm{H}) ; 6.80-6.52(\mathrm{q}, \mathrm{s}, \mathrm{dd}$,

$8 \quad 4 \mathrm{H}) ; 5.99-5.94(\mathrm{~d}, 1 \mathrm{H}) ; 5.48-5.36(\mathrm{~d}, 1 \mathrm{H}) ; 3.98-3.50(\mathrm{~m}, 20 \mathrm{H}) .{ }^{13} \mathrm{C}-\mathrm{NMR}(75 \mathrm{MHz} ; \mathrm{d}-$

$9 \quad \mathrm{DMSO} ; 298 \mathrm{~K}): \delta(\mathrm{ppm})=147.9 ; 145.46 ; 141.1 ; 138.4 ; 135.2 ; 130.54 ; 127.9 ; 127.15 ; 126.84$;

$10 \quad 126.63 ; 117.76 ; 113.93 ; 113.14 ; 107.7 ; 68.82 ; 69.74-67.97 . \mathrm{m} / \mathrm{z}(\mathrm{ESI}-\mathrm{HRMS}) 516.17\left(\left[\mathrm{MNa}^{+}\right]\right.$

$11 \quad \mathrm{C}_{24} \mathrm{H}_{31} \mathrm{NO}_{8} \mathrm{SNa}$ requires 516.57).

12

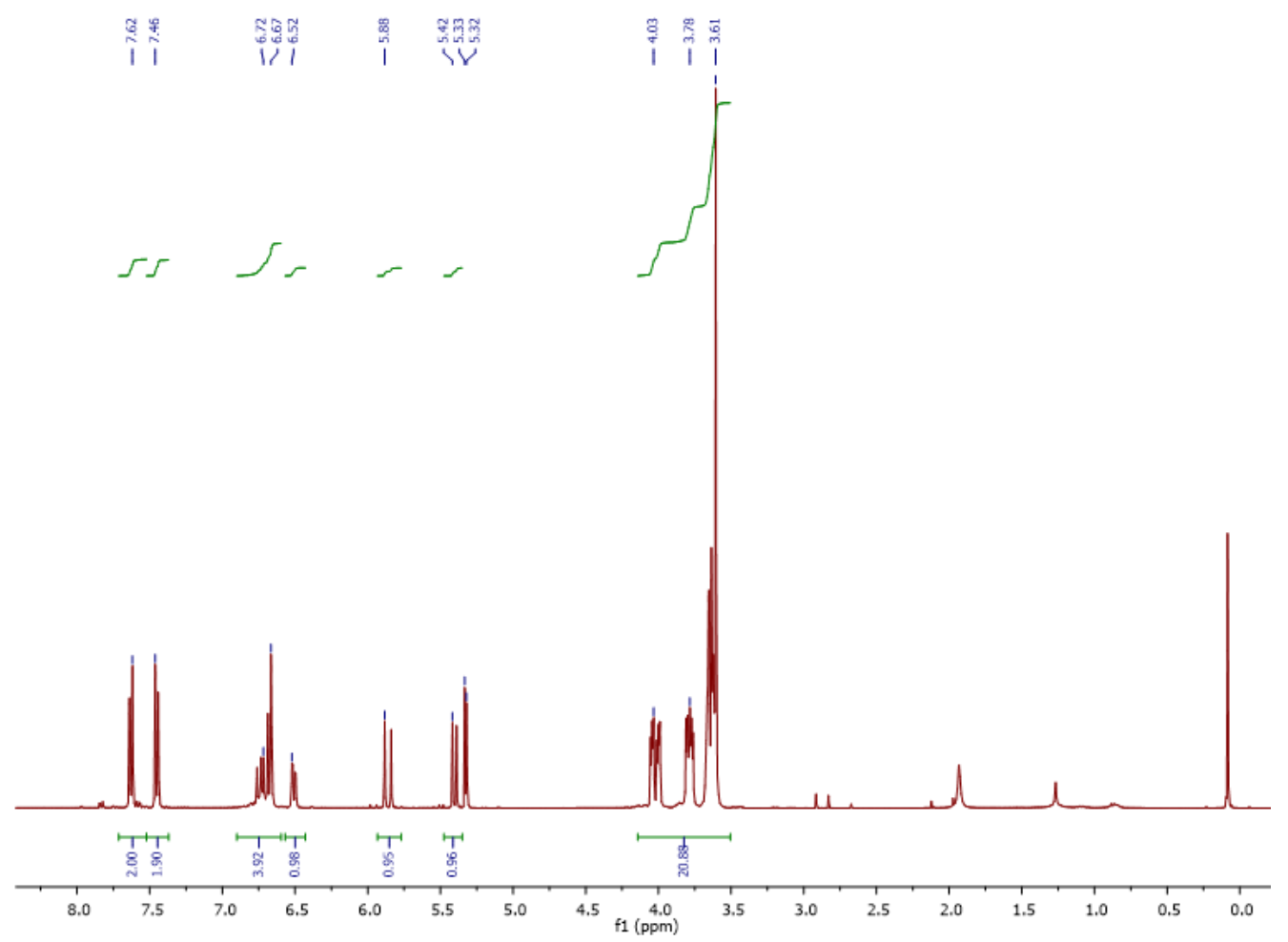

13 SI-1. ${ }^{1} \mathrm{H}-\mathrm{NMR}\left(\mathrm{CD}_{2} \mathrm{Cl}_{2}, 400 \mathrm{MHz}\right)$ of 4-styrenesulfonyl(phenyl-18-crown-6) imide (2). 


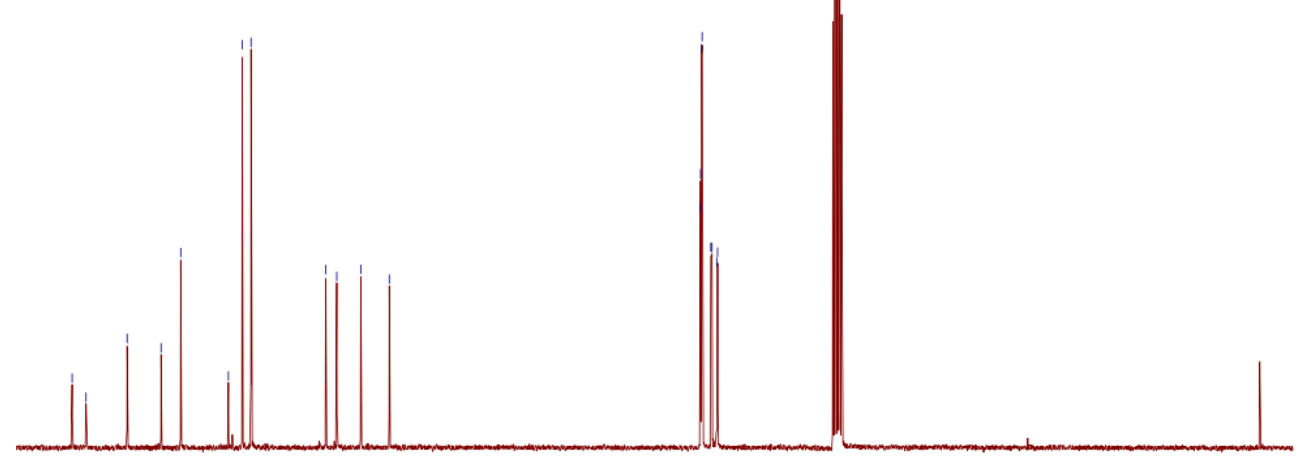

2 SI-2. ${ }^{13} \mathrm{C}-\mathrm{NMR}\left(\mathrm{CD}_{2} \mathrm{Cl}_{2}, 150 \mathrm{MHz}\right)$ of 4-styrenesulfonyl(phenyl-18-crown-6) imide (2)

3 Binding ability evaluation by ${ }^{1} H-N M R$ titration of monomer (2)

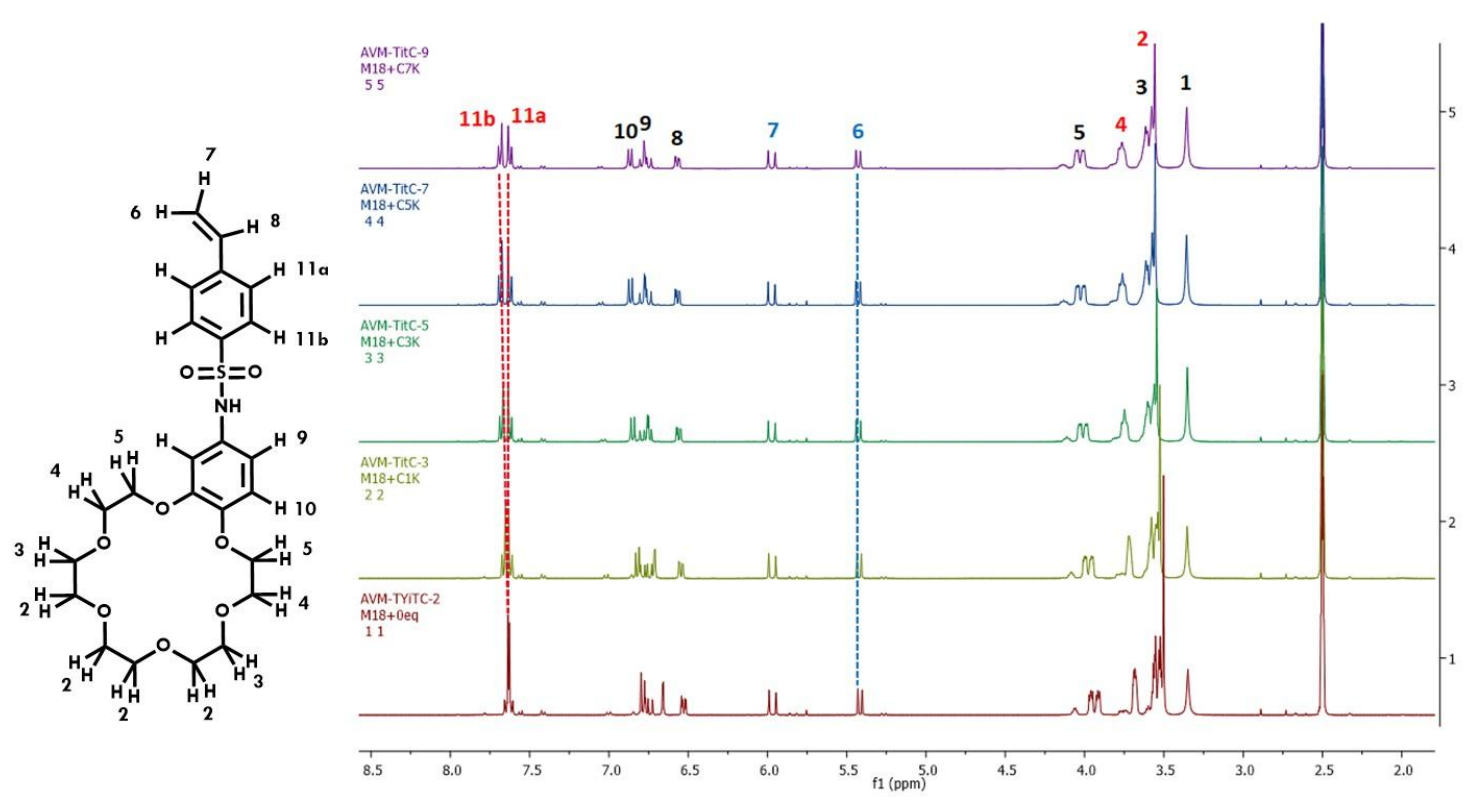

5 SI-3. ${ }^{1} \mathrm{H}-\mathrm{NMR}$ Spectrum (DMSO, $400 \mathrm{MHz}$ ) obtained for the titration of the monomer (2)

6 under variable concentrations (from 0 to 2 molar equivalents) of potassium perchlorate. 
WILEY-VCH

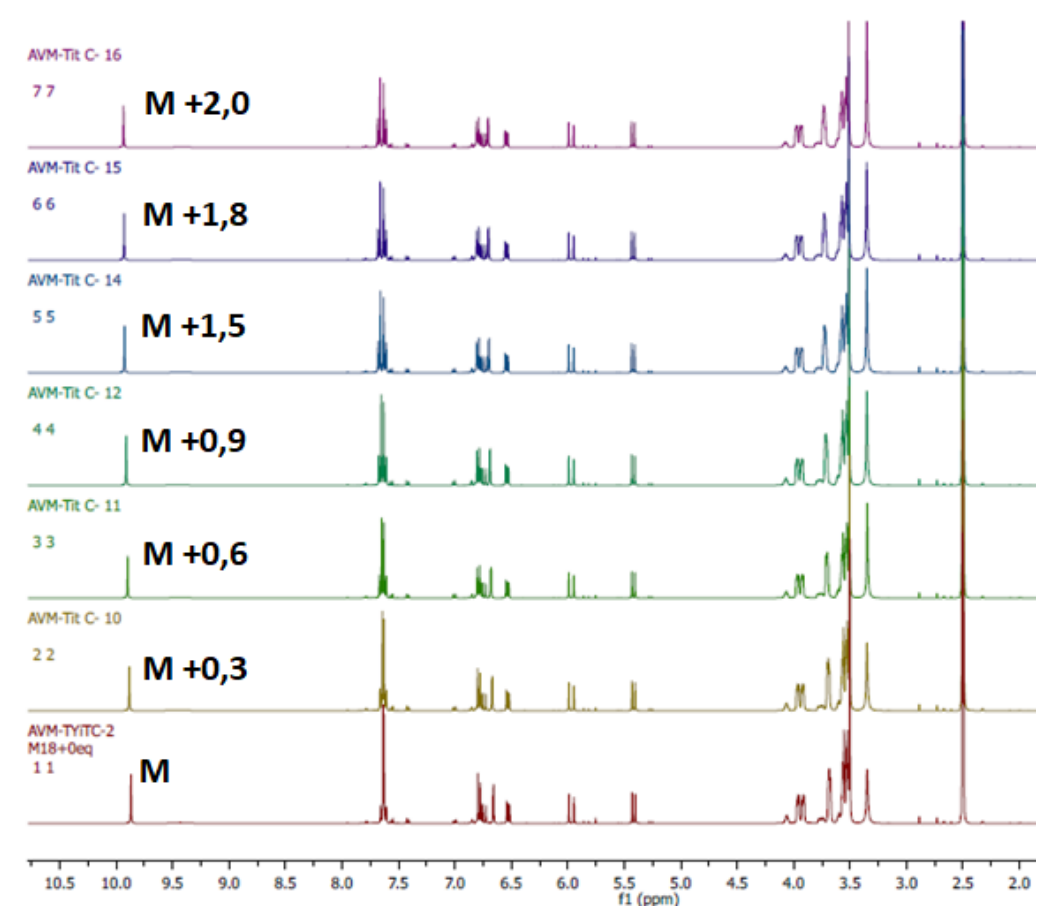

2 SI-4. ${ }^{1} \mathrm{H}-\mathrm{NMR}$ Spectrum (DMSO, $400 \mathrm{MHz}$ ) obtained for the titration of the monomer (2)

3 under variable concentrations (from 0 to 2 molar equivalents) of sodium perchlorate. 
WILEY-VCH
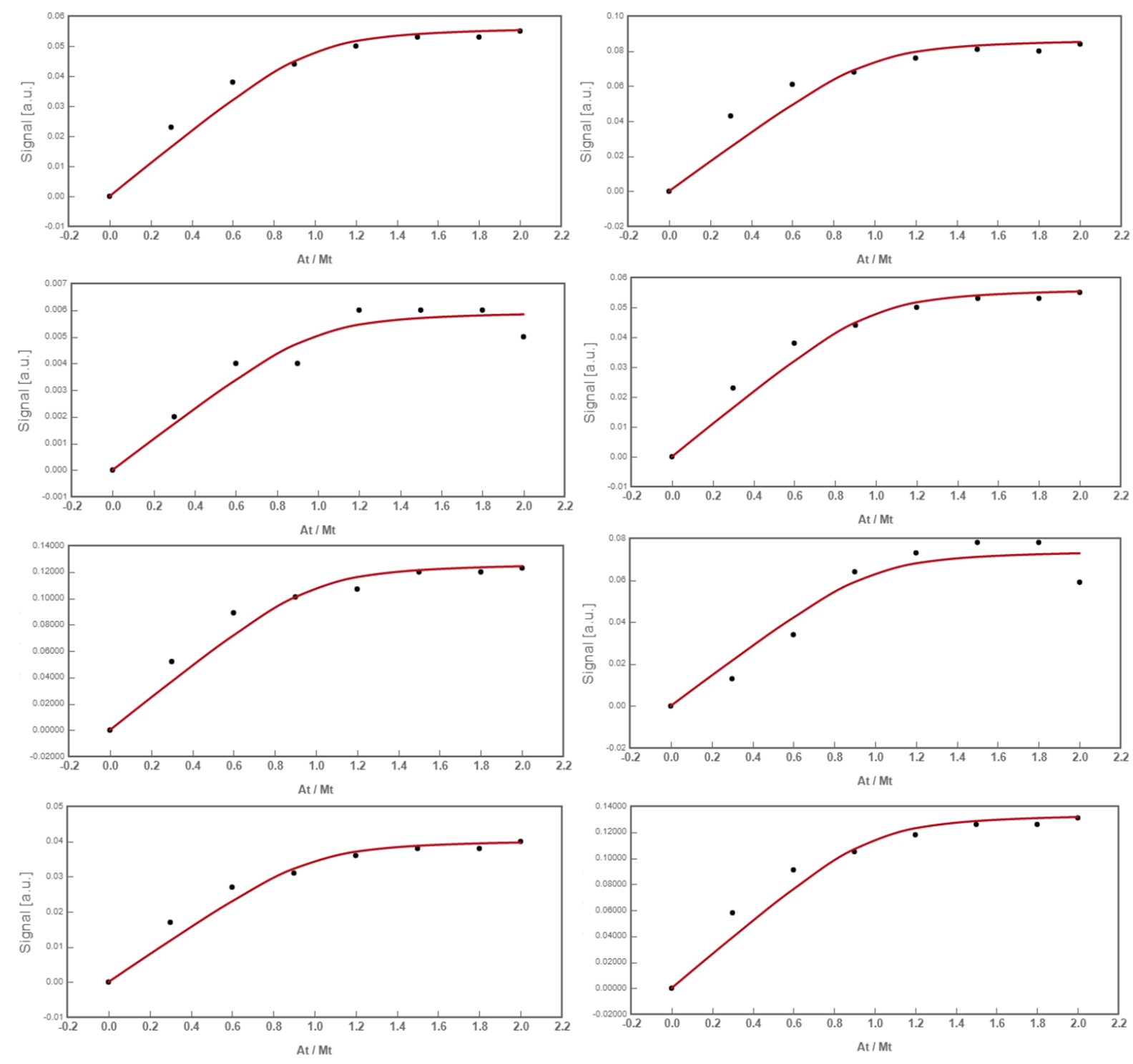

2 SI-5. Binding isotherms and fitting to a 1:1 binding model of the experimental data from ${ }^{1} \mathrm{H}-$

3 NMR titration of the monomer (2) (d-DMSO, $400 \mathrm{MHz})$. Scattered dots: Experimental data

4 obtained from the difference in NMR shift (ppm) with respect to initial monomer spectra (y-

5 axis - "Signal") vs the increasing concentration of $\mathrm{KClO}_{4}$, for a constant monomer

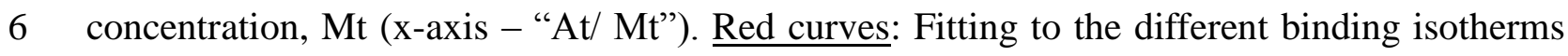

7 with a 1:1 binding model to obtain the global binding constant $\left(K_{A}\right)$. 


\section{WILEY-VCH}

1 Radical polymerization and Copolymerization (GENERAL PROCEDURE): The copolymers

2 between STFSI monomer and ion-sensitive styrene monomer (2) were synthesized by

3 reversible addition-fragmentation chain-transfer (RAFT) radical polymerization by mixing,

4 according to the targeted molar mass and composition, the proper quantity of the STFSI/(2)

5 monomers, chain transfer agent and azobisisobutyronitrile (AIBN) in DMF. After several

6 freeze-thaw cycles, the mixture was left to polymerize at $64^{\circ} \mathrm{C}$ from several hours to few

7 weeks, depending on the molar mass that should be obtained. The polymer was ready after

8 precipitation in tetrahydrofuran (THF) or the adequate solvent mixture, filtration, washing

9 with THF and drying in vacuum oven at $65^{\circ} \mathrm{C}$ for at least one day.

10

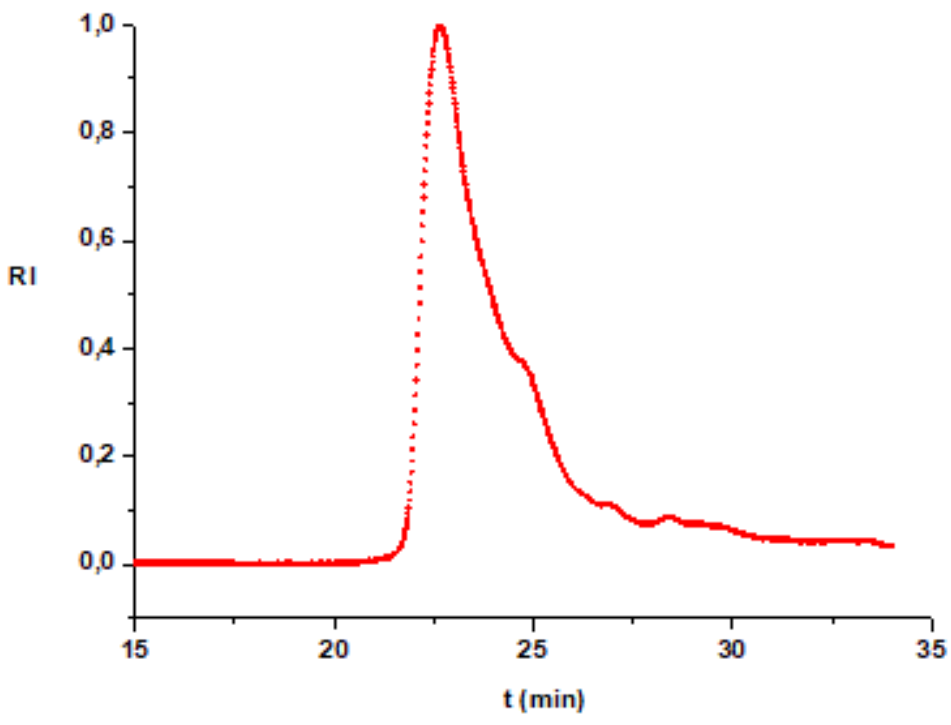

11 SI-6. Size exclusion chromatogram (SEC) of a copolymer between STFSI (wt.\% = 85) and

12 monomer (2) (wt.\% = 15) showing a main population of $135 \mathrm{kDa}$. Conditions: Polystyrene

13 standard calibration. $\mathrm{DMF}, \mathrm{LiBr}, 70^{\circ} \mathrm{C}$. 


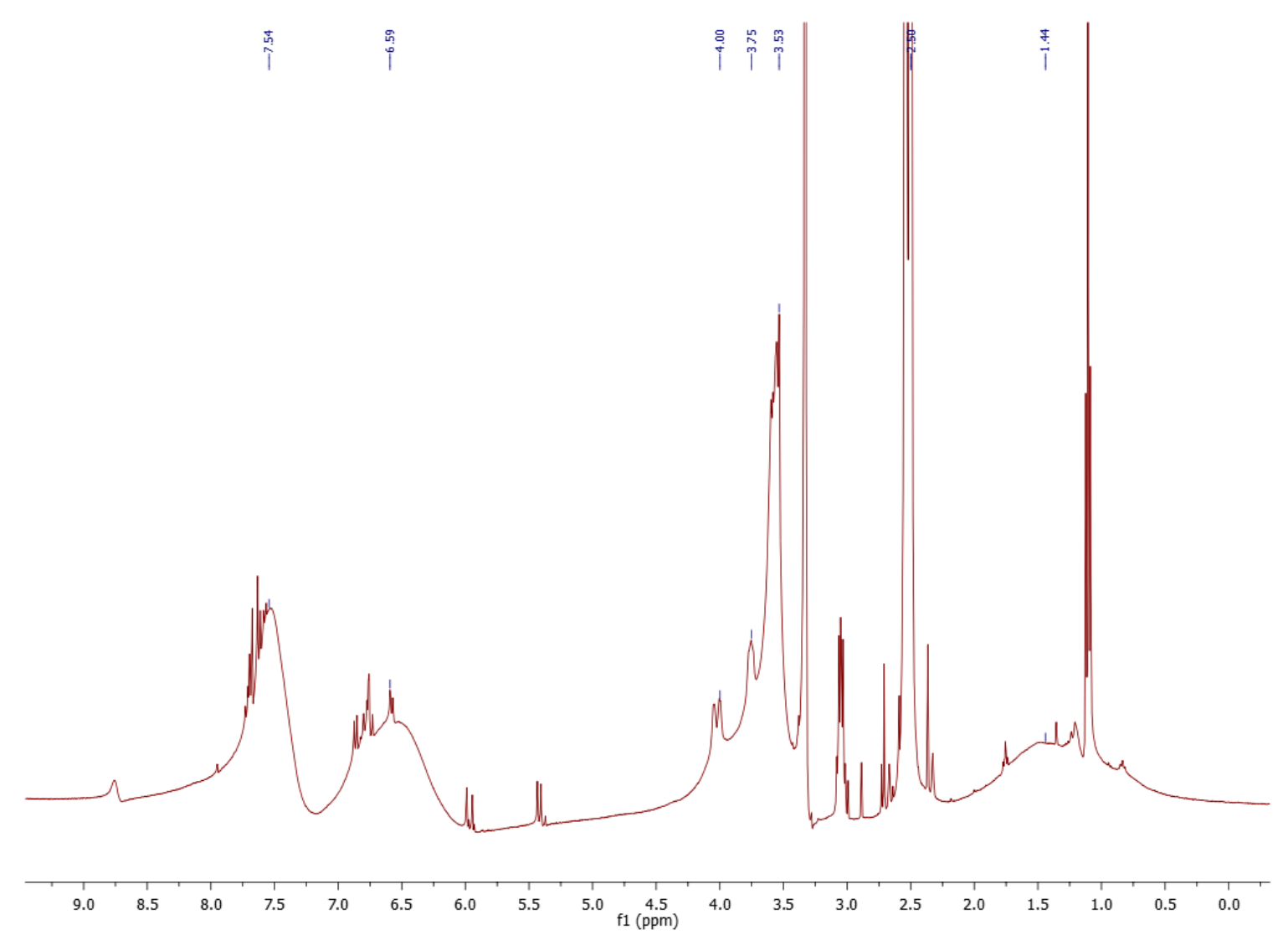

2 SI-7. ${ }^{1} \mathrm{H}-\mathrm{NMR}$ Spectrum $\left(\mathrm{d}_{6}\right.$-DMSO, $\left.400 \mathrm{MHz}\right)$ of a copolymer between STFSI $(w \mathrm{t} . \%=85)$

3 and monomer (2) (wt.\% = 15).

4 Conductive ion sensitive aqueous PEDOT dispersions: Solutions of iron chloride (III) (0.036 $5 \mathrm{mg}, 0.22 \mathrm{mmol})$, ammonium persulfate $(0.161 \mathrm{~g}, 0.71 \mathrm{mmol})$ and the styrene-based copolymer $(0.210 \mathrm{~g})$ were prepared in individual aqueous solutions and stirred during $5 \mathrm{~h}$

7 previous to their use. Afterwards, the polyelectrolyte solution was transferred to the reactor 8 and EDOT monomer was added $(0.038 \mathrm{~mL}, 0.36 \mathrm{mmol})$ keeping under nitrogen flow at $10^{\circ} \mathrm{C}$ 9 for $30 \mathrm{~min}$. Addition of the oxidant solutions composed of iron chloride and ammonium 10 persulfate starts the polymerization. The reaction is kept running under static inert atmosphere 11 during 64h. Purification has been done by ultrafiltration, washing firstly with $1 \mathrm{M}$ 12 hydrochloric acid $(150 \mathrm{~mL})$. After stirring for two more hours with a $50 \%$ content of the 13 previous used acid solution, a last washing with water was performed. Concentrations were 14 adjusted to about 1 weight $\%$ of content after filtration, in correlation with a calibration curve 


\section{WILEY-VCH}

1 obtained by UV-Vis absorption spectroscopy analysis. Inks were stored protected from light

2 at constant temperature and under stirring.

3 a)

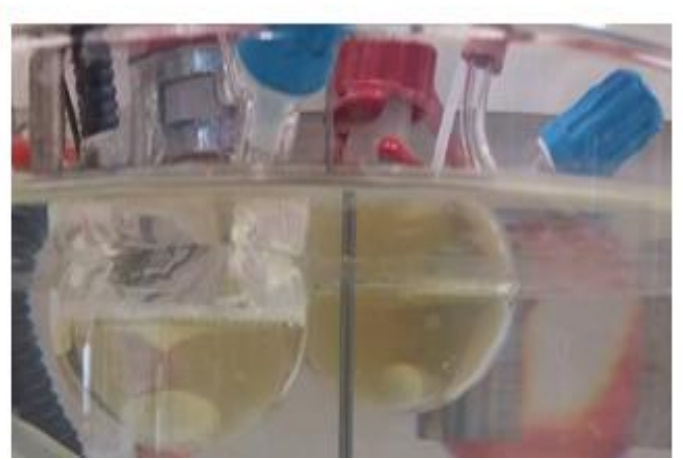

b)

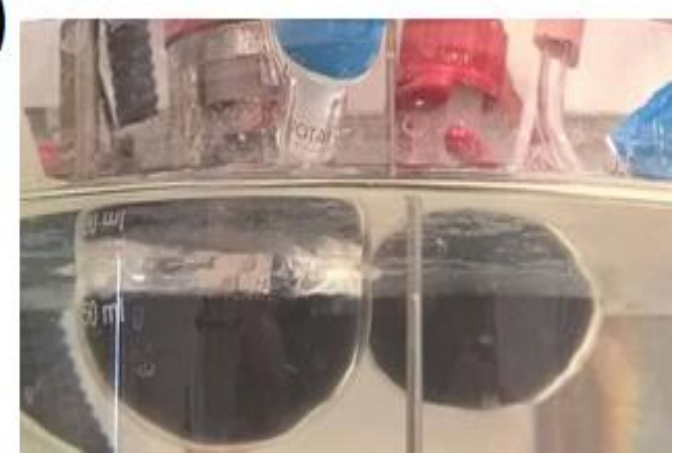

SI-8. Aqueous dispersion formation of the ion-sensitive PEDOT based ink: a) Before the addition of the oxidants, brownish polyelectrolyte solution; b) After addition of the oxidants, formation of the PEDOT based ink.

In-situ electrochemical-conductance measurements: In-situ electrochemical-conductance measurements were carried out using a two potentiostat system, specially built for this application. As working electrodes, DropSens interdigital microarrange electrodes (IDMAE), featuring separated $\mathrm{Pt}$ bands $(10 \mu \mathrm{m})$ deposited on it, were used. A three-electrode electrochemical cell fitted with a Pt foil counter electrode separated aproximatly $0.5 \mathrm{~cm}$ from the working electrode (parallel and of the same size as the working electrode), a pseudoreference electrode (Ag wire) and the IDMAE were used for the studies. A constant potential difference of $10 \mathrm{mV}$ provided by one potentiostat was applied between the IDMAE branches to generate the drain current that circulates through the polymer during conductance determinations. The conductance of the dropcasted films was measured in real time during the cyclic voltammetry experiment in an aqueous $0.1 \mathrm{M}$ tetramethyl ammonium chloride (TMAC) solution at $25{ }^{\circ} \mathrm{C}$. Conductance was calculated according to Ohm's Law, which is directly related with specific conductivity. More details about this technique and examples of 
1 the use of conductance measurements in conducting polymers can be found elsewhere in the

2 literature ${ }^{[2]}$
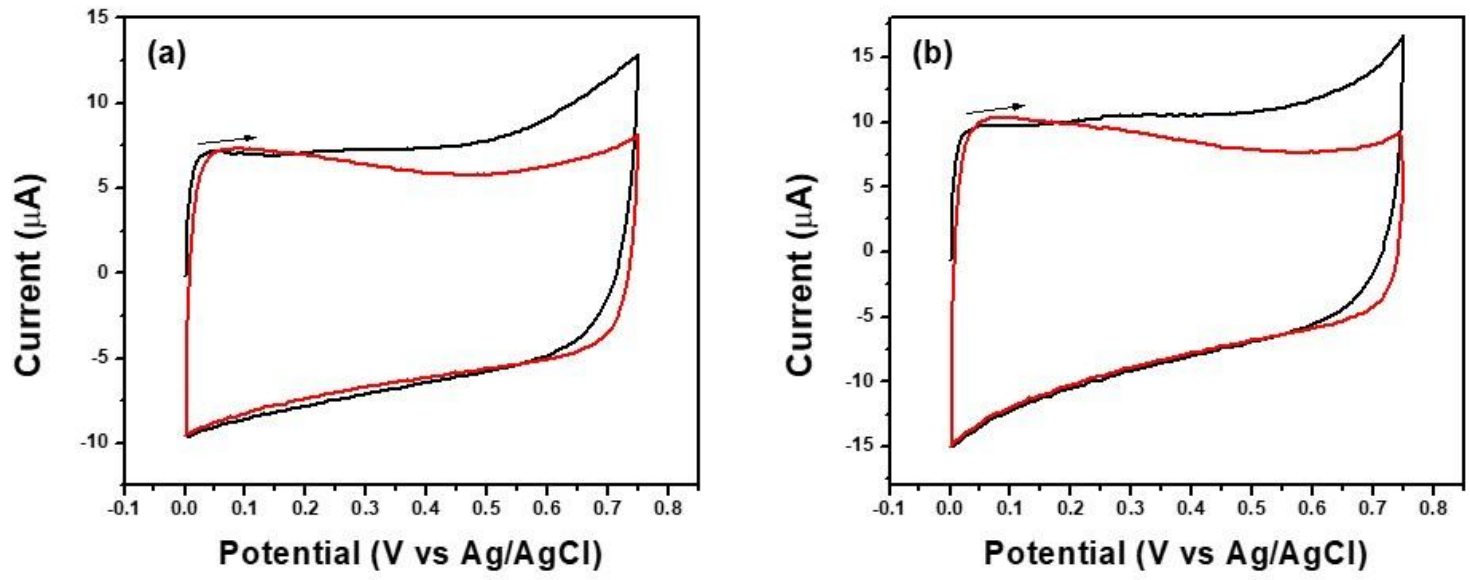

4 SI-9. Potentiodynamic response of PEDOT electropolymerized in the presence of (a) PSS and

(b) PSTFSI, in a free monomer $0.1 \mathrm{M}$ PSS aqueous solution, $v=50 \mathrm{mV} / \mathrm{s}, 1 \mathrm{st}$ cycle (black line) and 10th cycle (red line).
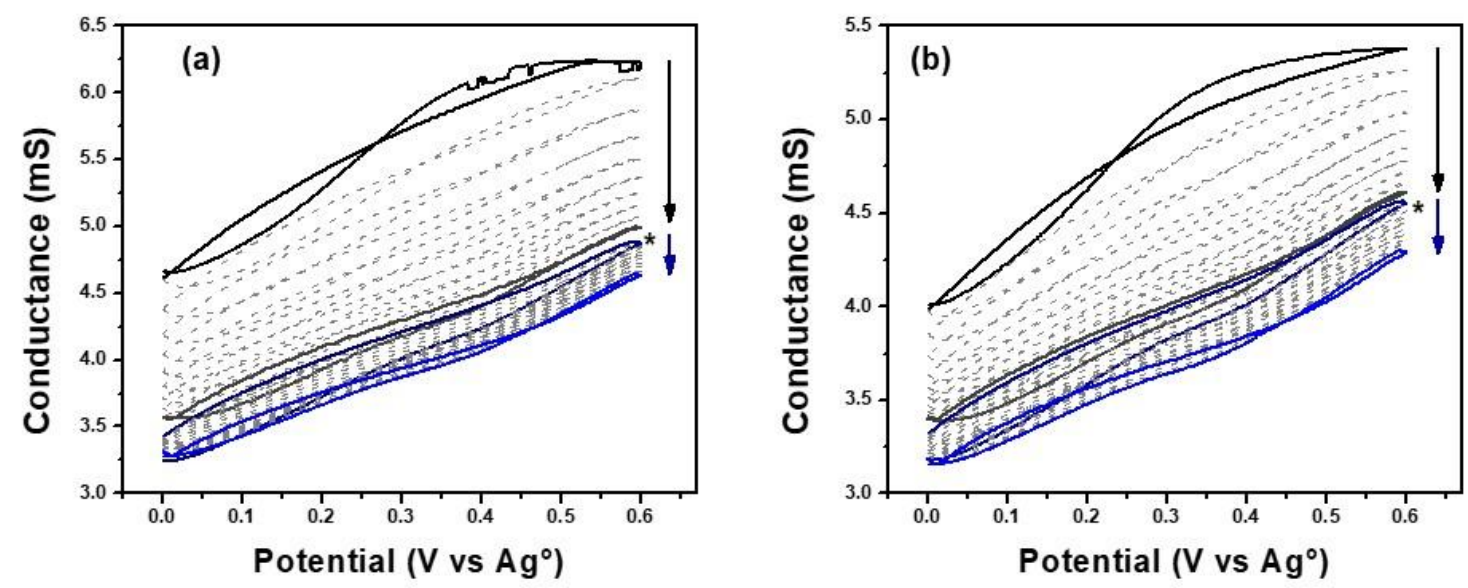

8 SI-10. Conductance profile of drop casted PEDOT/ P(STFSI85-co-S18cr615) films in a $0.1 \mathrm{M}$

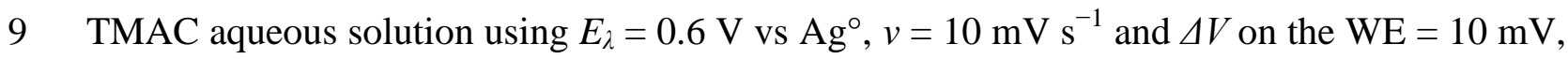

$10 \mathrm{WE}=\mathrm{Pt}$ IDMAE, $\mathrm{CE}=\mathrm{Pt}$ foil, in the absence (initial 10 cycles) and the presence of (a) 10

$11 \mathrm{mM} \mathrm{KCl}$ and (c) $10 \mathrm{mM} \mathrm{NaCl}$ (final 10 cycles). The asterisk indicates the moment when 12 addition of the chloride salts was performed. 

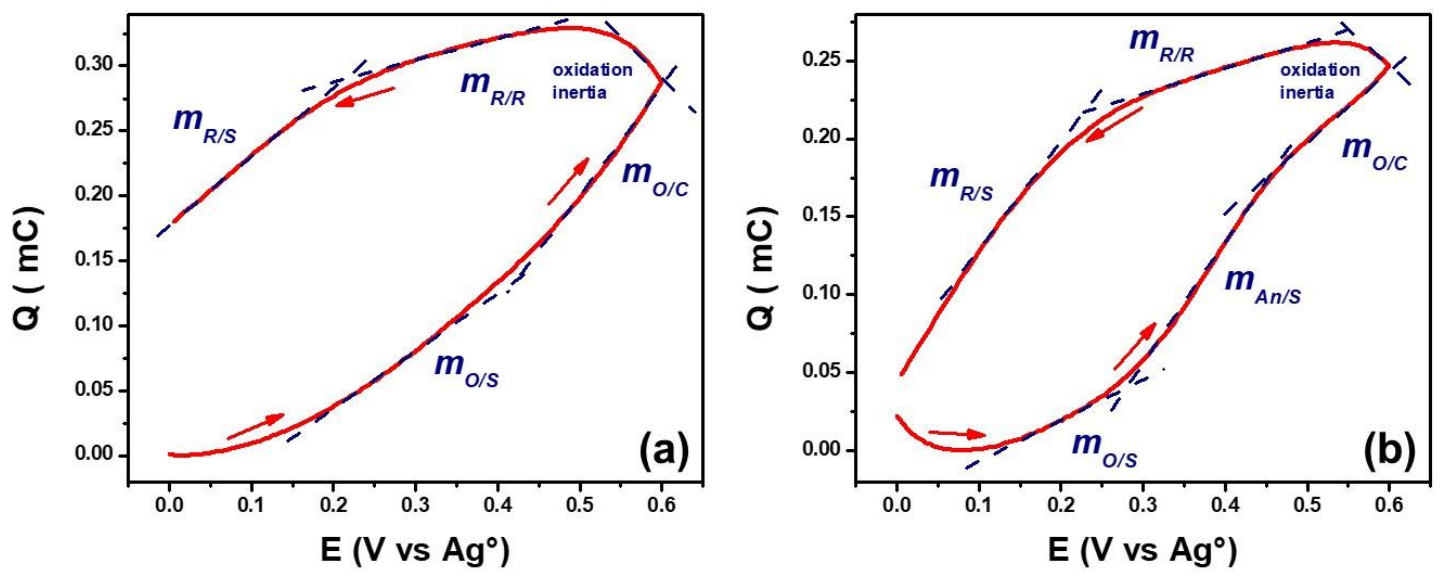

3 SI-11. Charge-potential plots of a drop-casted film in a $0.1 \mathrm{M}$ TMAC aqueous solution

4 obtained from the integration of the (a) 1st and (b) 10th potentiodynamic scan.

5 Cytotoxicity evaluation: direct evaluation and apoptosis test: Determination of the rate of

6 programmed cell death was performed by the use of a LIVE/DEAD Kit (ThermoFisher 7 Scientific, USA). This sensitive two-colour fluorescence cell viability assay allows 8 discrimination between alive and dead cells with two probes that measure established 9 parameters of cytotoxicity and cell viability, i.e. intracellular esterase activity and plasma 10 membrane integrity. Polymer films were deposited on coverslips (18 $\mathrm{mm}$ diameter). Prior to 11 use, they were washed (by sonication in acetone, ethanol and isopropanol baths), air dried and 12 activated (surface plasma cleaning, 15min). Films were formed by spin-coating of the ink 13 (previously formulated) at the optimal speed to obtain maximal film coverage (generally for $1430 \mathrm{~s}$ at $500-800 \mathrm{rpm}$, followed by a cycle at $1200-1800 \mathrm{rpm})$. Coated coverslips were cured at $1550^{\circ} \mathrm{C}$ for $10 \mathrm{~min}$ followed by heating to $120^{\circ} \mathrm{C}$ for one hour. After cooling, films were placed 16 in a 12 well multiwall that had been sterilized by UV treatment ( $\lambda=254 \mathrm{~nm}, 30 \mathrm{~min})$ prior to 17 cell culture. Before adding cells in the medium, coverslips were rinsed with $1.5 \mathrm{ml} / \mathrm{well}$ of $18 \mathrm{PBS}+/+$ buffer (composition in mM: $\mathrm{KCl} 2.67 ; \mathrm{KH}_{2} \mathrm{PO}_{4} 1.67 ; \mathrm{NaCl} 138, \mathrm{Na}_{2} \mathrm{PO}_{4} 8, \mathrm{CaCl}_{2} 1.8$, 


\section{WILEY-VCH}

$1 \mathrm{MgCl}_{2}$ 1.0) and dried overnight. 50,000 INS-1 clonal $\beta$-cells were added per well and cultured

2 as described for 3 days. ${ }^{[3]}$ Coverslips were either visualized and documented by phase contrast

3 microscopy or further processed for apoptosis measurements. In the latter case, cell media

4 were replaced by fresh media with or without thapsigargin $(0.1 \mu \mathrm{M}$, as positive control $)$ for $6 \mathrm{~h}$

5 prior to analysis. Imaging was used after de-freeze. The Live/Dead cell kit was used

6 according to the manufacturer and $150 \mu \mathrm{L}$ of final solution were added per coverslip for 15

7 min at $37^{\circ} \mathrm{C}$ followed by imaging. For each data point three coverslips were examined,

8 experiments were repeated independently nine times and areas of fluorescence calculated by

9 ImageJ. ${ }^{[4]}$ Statistical analysis was performed using GraphPad Prism7.

\section{References}

11 [1] Data fitting was performed with the AFFINImeter server (http://www.affinimeter.com).

12 Unless stated otherwise the experimental data were fitted using a simple 1:1 binding model.

13 [2] G. Salinas, B. A. Frontana-Uribe, ChemElectroChem 2019, 6, 4105.

14 [3] B. Hastoy, P. A. Scotti, A. Milochau, Z. Fezoua-Boubegtiten, J. Rodas, R. Megret, 15 Scientific Reports 2017, 7, 2835.

16 [4] ImageJ2: ImageJ for the next generation of scientific image data", BMC Bioinformatics $17 \quad 18,529$, 